MATEC Web of Conferences 17, 01017 (2014)

DOI: $10.1051 /$ matecconf/ 20141701017

(C) Owned by the authors, published by EDP Sciences, 2014

\title{
Porous Pavers: Effects of the Recycled Aggregate Size on Drainage Properties
}

\author{
A.N. Abdul Ghani ${ }^{1}$, P.C. Cheong ${ }^{2, a}$ \\ ${ }^{1,2}$ School of Housing, Building and Planning, Universiti Sains Malaysia, 11800, Penang, Malaysia
}

\begin{abstract}
Pervious pavers allow water to percolate through the pavement surface. One of its functions is to reduce runoff. This research studies the possible usage of recycled aggregates as the main base material for pervious pavers. Recycled aggregates are produced by crushing waste concrete and mixing with a non-cement, epoxy binder to produce a pervious pavement. The samples were tested for permeability, porosity and compressive strength. The effects of using recycled aggregates and epoxy binders on the mechanical and physical properties are examined. Mixed proportions of several sizes of recycled aggregates were carried out in order to identify its drainage properties. The permeability test indicated an outstanding result which is 10 times more permeable compared to previous studies. A high porosity was also recorded, up to 2 times more porous than conventional pervious pavers bound with cement. Also, the result of the compressive strength of pervious pavers bound with epoxy binders has shown enough strength for light usage purposes. It can be concluded that the construction of pervious pavers using recycled aggregates with epoxy binders is suitable for pedestrian and light traffic usage.
\end{abstract}

\section{Introduction}

In recent years, urban development has brought troubling effects to the environment. Major changes occurred to stream, lake and river depths. All of these changes are caused by uncontrolled stormwater runoff from developed real estate [1]. Concrete surfaces are found most in developed real estate. This causes the rainwater to tend to run off the concrete surface rather than being retained by soil or vegetation. As a result, the changes such as stream bank erosion, waterway pollution and downstream flooding occurs. As such, it is important to adopt an alternative way to solve these problems and the negative changes which affect the environment. The need for pervious surfaces has also grown, and today the proper use of pervious concrete is among the recommended Best Management Practice (BMPs) of the US Environmental Protection Agency (EPA) [2]. Pervious concrete is usually a mixture of gravel or stone, cement, water and little or no sand which creates an open cell structure that allows water and air to pass through [3]. Numerous researches have been carried out on the subject of pervious concrete in the past. Unfortunately, no technical data and information are available on the drainage capacity of pervious pavers using recycled aggregates and non-cement based binders in Malaysia. Malaysia is a high humidity country with an annual rainfall volume of up to 320 billion cubic metres (bcm) for Peninsula Malaysia, $194 \mathrm{bcm}$ for Sabah and 476 bcm for Sarawak [4]. Therefore it is important to fully utilize the benefits of pervious pavers in 
stormwater control. Typically, pervious concrete has a void content of 15 to $25 \%$. The addition of a small amount of fine aggregate will generally reduce the void content and increase the strength [5].

Recycled aggregate refers to particles obtained through certain operations such as the crushing, sieving and grading of waste concrete. Recycled aggregate has a weaker water absorption ratio and crushing value which brings about the issue of the difficulty in producing higher strength recycled aggregate concrete, as a result limited its wide application [6]. The properties of recycled concrete have always been linked to its strength. It was found that the concrete strength decreased when recycled concrete was used. Its reduction in strength could be as low as $40 \%$ [7]. No decrease in the concrete strength was found when the concrete contained up to $20 \%$ fine or $30 \%$ coarse recycled concrete aggregate. However when the percentage of usage went beyond these levels, it showed a systematic decrease in the concrete strength. The relationship of the recycled concrete aggregate to the concrete strength is in an inversely proportional manner, where when the quantity of recycled aggregate increased, the concrete strength decreased [8].

Previous research done on the effects of the aggregate size and gradation towards the properties of the pervious concrete showed that when the uniformity coefficients of the aggregate increased, which means the gradation became less uniform or single sized and more well graded, the strength also increased, whereas the porosity and permeability decreased [9]. The porosity of pervious concrete can be defined differently. Measurable voids are defined as the effective porosity since this relates to permeability, and the overall air content is accordingly defined as total porosity [11].

Epoxy resin is used as a supplementary cementing material for the production of epoxy modified concrete. The replacing of part of the cement with epoxy resin was found to improve the strength, ductility, chemical resistance and durability of the concrete. The improvement of the compressive strength of the concrete is linearly proportional to the epoxy/cement ratio [12]. However there is no technical data available on the use of epoxy resin as the only binder of course aggregates. Hence, this study is intended to determine the effect of the drainage capacity of cement free recycled aggregate pavers by determining its permeability and the porosity of the cubes produced from recycled aggregates.

\section{Materials}

\subsection{Recycled Aggregate}

For this study, recycled aggregates are used as the main component in the pervious paver. The old concrete was obtained from the Concrete Laboratory of School of Housing, Building and Planning, USM. The old concrete cubes were gathered to be crushed into smaller pieces. The recycled aggregates were sieved into several groups of $5 \mathrm{~mm}$ and $10 \mathrm{~mm}$ sizes. Table 1 shows the size of the sieve that the aggregate passed through and retained on.

Table 1: Size of aggregate sieve

\begin{tabular}{|c|c|}
\hline Size of sieve (passes through) & Size of sieve (retained on) \\
\hline $14 \mathrm{~mm}$ & $10 \mathrm{~mm}$ \\
\hline $10 \mathrm{~mm}$ & $5 \mathrm{~mm}$ \\
\hline
\end{tabular}

\subsection{Epoxy Resin with Hardener}

Epoxy was used as the only binder in this study. It is known as a two-part liquid epoxy thermosetting resin system. It is grouped under synthetic resin and plastics. Both the epoxy resin and hardener are in liquid form. The epoxy resin is in clear form while the hardener is yellow. The code number of the epoxy resin used is CP 370A, manufactured by Oriental Option Sdn. Bhd. The mixing ratio of epoxy resin to hardener is 1 to 1 . 


\section{Experimental Set-up}

For this study, a preliminary test was done in order to obtain the suitable percentage of epoxy binder to be used in the mix proportions. A total of 13 samples were produced in the preliminary test. Table 2 shows the mix proportions of the preliminary samples.

Table 2: Mix proportion of preliminary samples

\begin{tabular}{|c|c|c|c|c|c|c|c|}
\hline Sample & $\begin{array}{c}\text { Size of } \\
\text { aggregate, } \\
\text { part 1 } \\
(\mathbf{m m})\end{array}$ & $\begin{array}{c}\text { Size of } \\
\text { aggregate, } \\
\text { part 2 } \\
(\mathbf{m m})\end{array}$ & $\begin{array}{c}\text { Weight of } \\
\text { recycled } \\
\text { aggregate, } \\
\text { part 1 (g) }\end{array}$ & $\begin{array}{c}\text { Weight of } \\
\text { recycled } \\
\text { aggregate, } \\
\text { part 2 (g) }\end{array}$ & $\begin{array}{c}\text { Epoxy } \\
\text { resin } \\
\mathbf{( \% )}\end{array}$ & $\begin{array}{c}\text { Hardener } \\
\mathbf{( \% )}\end{array}$ & $\begin{array}{c}\text { Total } \\
\text { epoxy } \\
\text { binder } \\
\mathbf{( \% )}\end{array}$ \\
\hline P1 & 5 & - & 1215 & - & 5 & 5 & 10 \\
\hline P2 & 5 & - & 1215 & - & 5 & 5 & 10 \\
\hline P3 & 10 & - & 1308 & - & 5 & 5 & 10 \\
\hline P4 & 10 & - & 1308 & - & 5 & 5 & 10 \\
\hline P5 & 5 & - & 1215 & - & 2.5 & 2.5 & 5 \\
\hline P6 & 5 & - & 1215 & - & 2.5 & 2.5 & 5 \\
\hline P8 & 10 & - & 1308 & - & 2.5 & 2.5 & 5 \\
\hline P9 & 10 & - & 1308 & - & 2.5 & 2.5 & 5 \\
\hline P10 & 5 & 10 & 525 & 779 & 2.5 & 2.5 & 5 \\
\hline P11 & 5 & 10 & 525 & 779 & 2.5 & 2.5 & 5 \\
\hline P12 & 5 & 10 & 525 & 779 & 4 & 4 & 8 \\
\hline P13 & 5 & 10 & 525 & 779 & 4 & 4 & 8 \\
\hline
\end{tabular}

The recycled aggregate and epoxy binder were mixed by hand and compacted by a $10 \mathrm{~kg}$ load. Each sample is left for 1 day at room temperature before the mould is removed. A thick layer of bleeding was found at the bottom of the samples with $10 \%$ epoxy binder. It was observed that the epoxy binder was still soft after removing the mould. However, it was found that when the epoxy binder was reduced to $5 \%$, the samples showed no bleeding. In order to identify if the mixture of the aggregate can reduce the effect of bleeding, mixtures of $5 \mathrm{~mm}$ and $10 \mathrm{~mm}$ aggregates were used to form 4 samples. When the percentage of the epoxy binder used were $8 \%$ for the mixture samples, a thinner layer of bleeding showed in the samples. No bleeding happened when it was reduced to $5 \%$.

After physical observation on the preliminary samples was done, it was found that when a high percentage of epoxy binder was used, a thick layer of bleeding was formed at the bottom of the sample, preventing water from passing through. Since no bleeding occurred for all the samples using $5 \%$, therefore $5 \%$ of epoxy binder by weight was chosen to be cast in the following samples in this study. A total of 6 samples with dimensions $100 \mathrm{~mm} \times 100 \mathrm{~mm} \times 100 \mathrm{~mm}$ were produced with $5 \%$ epoxy binder. All these 6 samples were further tested with porosity test, permeability test and compressive strength test. Figure 1 and 2 are the specimens in this study.

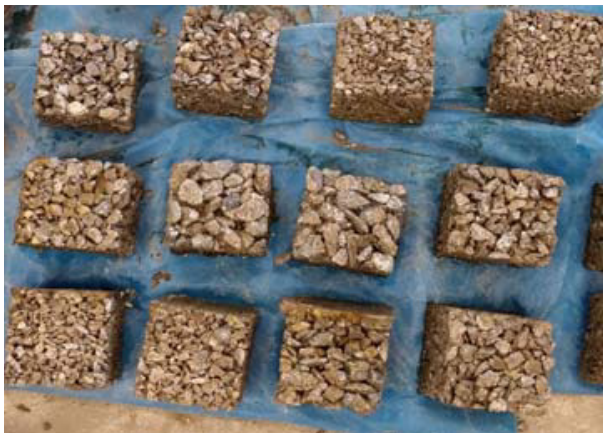

Fig 1: Various mixed design specimens

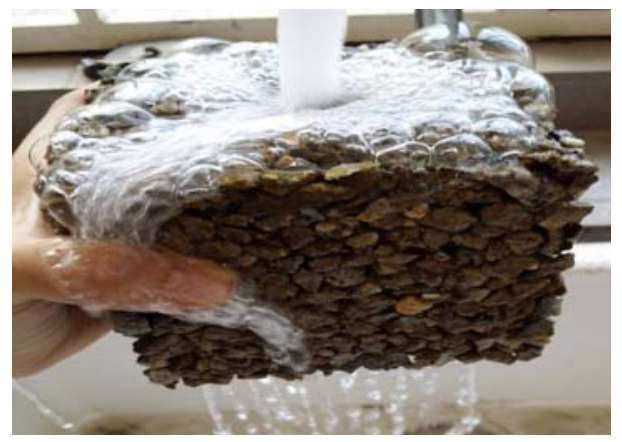

Fig 2: Porous paver characteristics 


\section{Results and Discussion}

\subsection{Porosity Test}

The results obtained for the porosity of specimen are shown in Table 3 . The porosity test was conducted by submerging the sample into a container full with water. The water displaced from the container is measured in volume. The water displaced is identified as the volume of voids. Porosity in $\%$ is calculated by the formula of volume of void divided by volume of sample.

Table 3: Porosity of samples

\begin{tabular}{|c|c|c|}
\hline Sample & Size of aggregate (mm) & Porosity (\%) \\
\hline A1 & 5 & 52.35 \\
\hline A2 33 & 5 & 53.18 \\
\hline A4 & 10 & 60.00 \\
\hline A5 & 10 & 67.00 \\
\hline A6 & $5+10$ & 54.73 \\
\hline
\end{tabular}

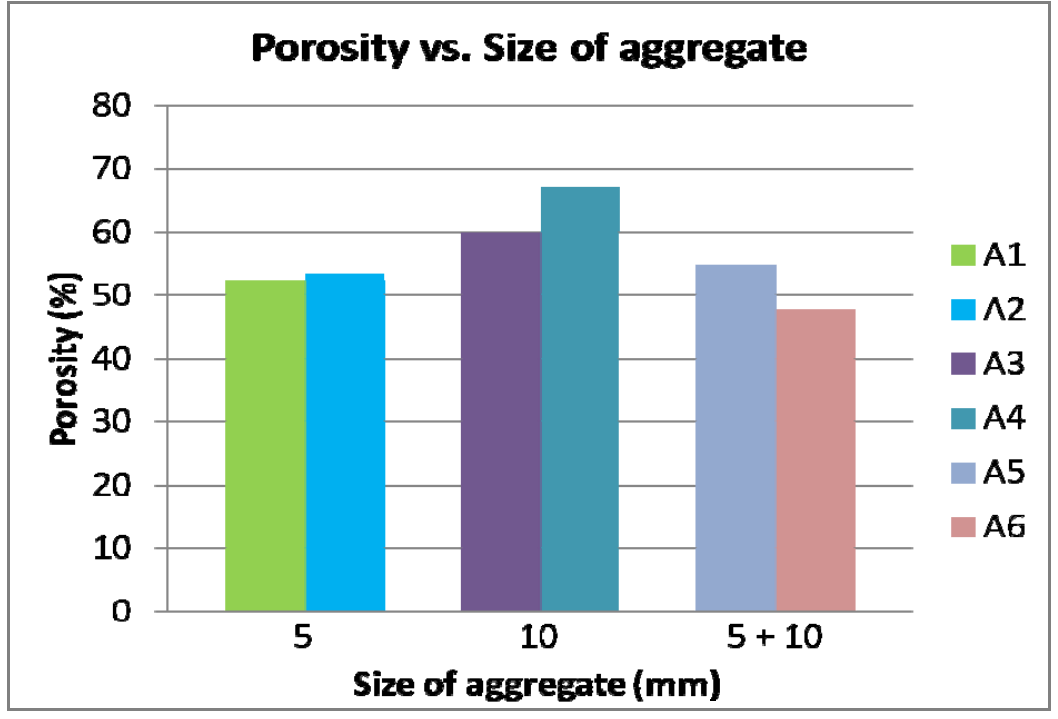

Fig. 3: Effect of size of aggregate

From Fig. 3, it is shown that samples with an aggregate size of $10 \mathrm{~mm}$ have the highest porosity with a recorded reading of $67 \%$. The lowest recorded reading is $47.80 \%$, which is the sample with a mixture of aggregate sizes of $5 \mathrm{~mm}$ and $10 \mathrm{~mm}$. This is because a larger aggregate size creates a larger void ratio and produces a more porous sample. In a previous study done by Lian et al. [11], using a coarse aggregate size of $9.5-4.75 \mathrm{~mm}$ had recorded a porosity of $31 \%$. The porosity obtained in this study was 2 times higher than the porosity gained by the Lian study.

\subsection{Permeability Test}

In this study, the permeability of the sample was measured with a device constructed as recommended by Yang and Jiang [13]. This parameter is important in a pervious paver because it can determine the drainage capacity of a successfully designed pervious paver. The permeability of the sample is identified as the water penetration coefficient in this study. The results are shown in Table 4. 
Table 4: Permeability of samples

\begin{tabular}{|c|c|c|}
\hline Sample & Size of aggregate (mm) & Water penetration coefficient (mm/s) \\
\hline A1 & 5 & 38.00 \\
\hline A2 & 5 & 55.10 \\
\hline A3 4 & 10 & 53.80 \\
\hline A5 & 10 & 49.50 \\
\hline A6 & $5+10$ & 67.80 \\
\hline
\end{tabular}

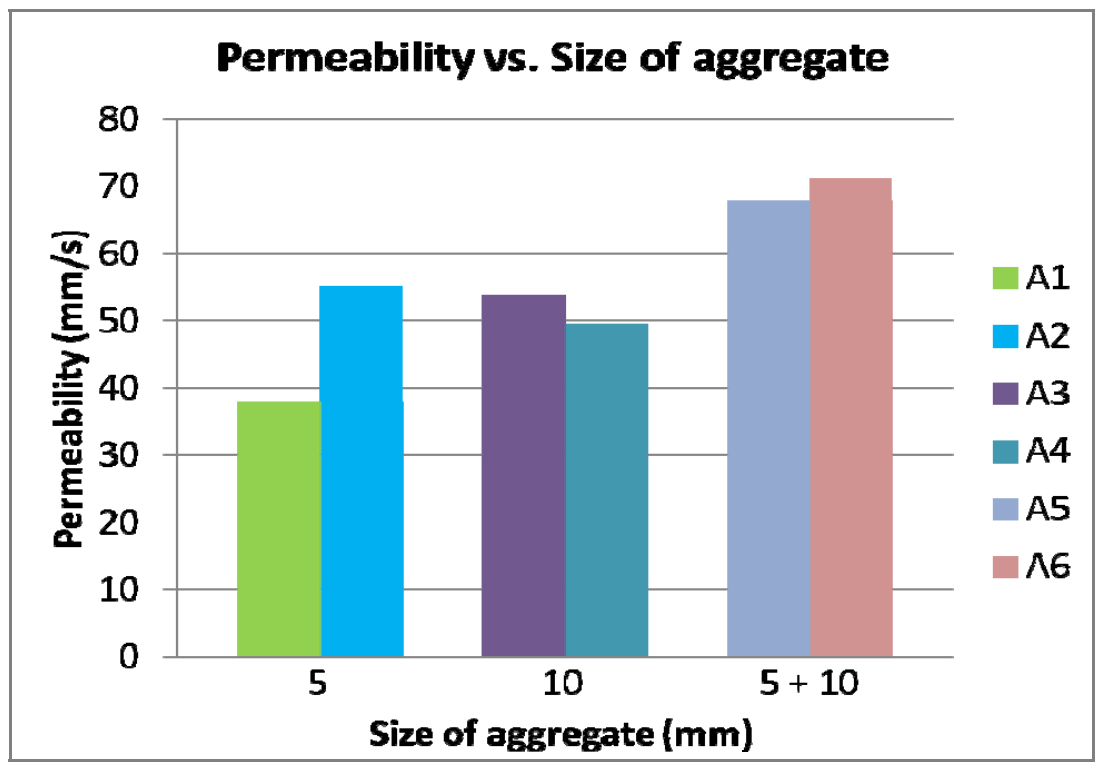

Fig. 4: Effect of size of aggregate on the water penetration coefficient

From Fig. 4, it can be seen that the sample with a mixture of aggregate sizes of $5 \mathrm{~mm}$ and $10 \mathrm{~mm}$ has the highest water penetration coefficient of $71.20 \%$. The sample with the aggregate size of $5 \mathrm{~mm}$ has the lowest water penetration coefficient of 38\%. In the Yang and Jiang study, aggregates of 5$10 \mathrm{~mm}$ with a binder of ordinary Portland cement were used to form the pervious concrete. The recorded water penetration coefficient recorded in their study is $8.9 \mathrm{~mm} / \mathrm{s}$. The permeability test results obtained in this study is as high as 10 times more than the result gathered from previous researcher.

\subsection{Compressive strength test}

All the 6 samples were tested for compressive strength. The highest loadings that the samples could withstand were recorded. A compressive strength test machine was used to identify the compressive strength. In this study, it was found that failure did not occur like conventional concrete during compression. Therefore, only the maximum load the sample could withstand was recorded. The results of the compressive strength test for the specimens are shown in Table 5, and Fig. 5 shows the compressive strength in relation to the size of the aggregate for the tested specimens. Also, from Table 5, the mixture of $5 \mathrm{~mm}$ and $10 \mathrm{~mm}$ aggregates samples show the highest reading of compressive strength. 


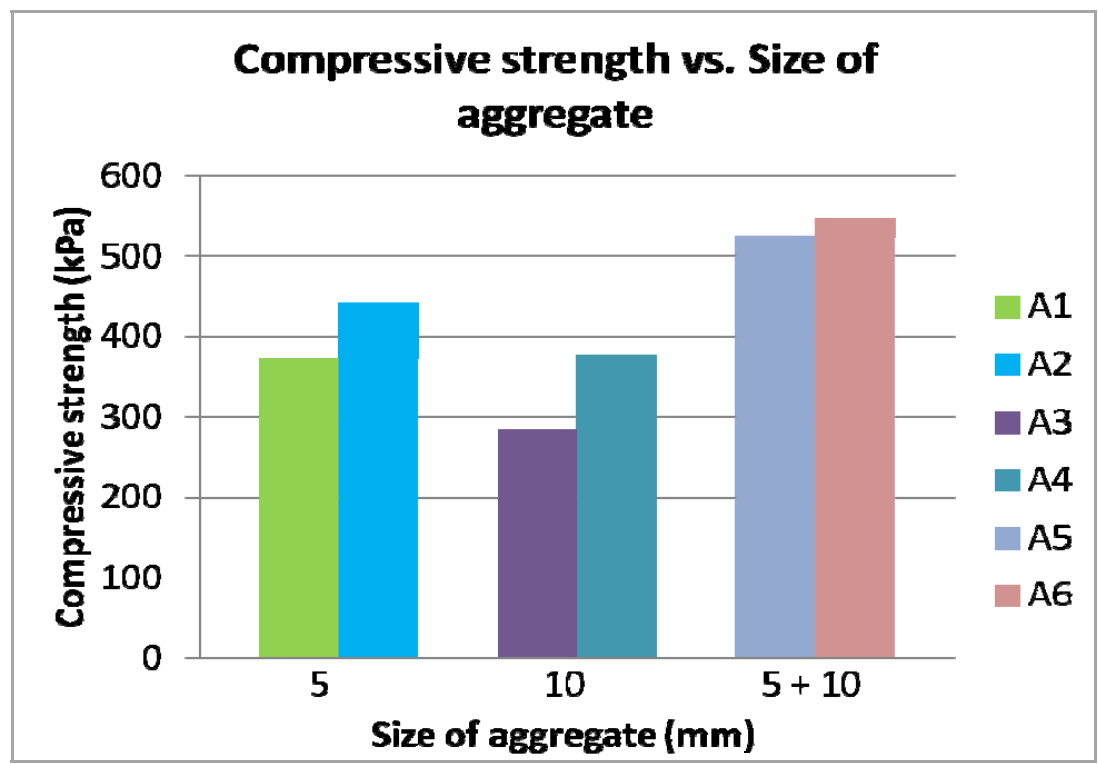

Fig. 5: Effect of size of aggregate on the compressive strength

Table 5: Compressive of samples

\begin{tabular}{|c|c|c|}
\hline Sample & Size of aggregate (mm) & Maximum load (kPA) \\
\hline A1 & 5 & 370 \\
\hline A2 & 5 & 440 \\
\hline A3 & 10 & 290 \\
\hline A4 & 10 & 380 \\
\hline A5 & $5+10$ & 520 \\
\hline A6 & $5+10$ & 550 \\
\hline
\end{tabular}

From Fig. 5, it can be seen that samples with a mixture of aggregate sizes of $5 \mathrm{~mm}$ and $10 \mathrm{~mm}$ have the highest compressive strength. The highest recorded reading is $550 \mathrm{kPa}$. The lowest recorded reading is $290 \mathrm{kPa}$, which is the sample with the aggregate size of $10 \mathrm{~mm}$. The overall compressive strength results showed sufficient compressive strength for light usage purposes.

\section{Conclusions}

This study had described all the processes from the primary stages of concrete cube recycling which involves breaking and crushing the existing concrete cubes or blocks into recycled aggregates, mix proportion of the epoxy binder pervious paver up to the analysis of the data obtained. Experimental laboratory works were carried out to obtain the data for compressive strength, porosity and permeability analysis. In conclusion, recycled aggregates are suitable to be used as the main material in pervious pavers. Pervious pavers using recycled aggregates from waste crushed concrete were successfully developed with acceptable high permeability and porosity. The porosity results obtained were two times higher than the results of previous studies done by other researchers. This can be due to the replacement of epoxy resin as the binder instead of ordinary Portland cement. Also, the permeability results showed a high water penetration coefficient, about ten times more permeable as compared to previous studies done by other researchers. The extreme difference can be due to the permeability test method adopted which was previously designed to test the permeability of cement pervious pavers instead of epoxy pervious pavers. The method adopted may not have provided an accurate 
result. A new method of testing the permeability of epoxy pervious pavers should be invented in order to obtain a more accurate result. Based on the data gathered and analysis done, pervious pavers formed with epoxy binders indicate very good porosity and permeability characteristics. Further, sufficient strength is achieved and it is suitable to be formed as the paver for light usage such as pedestrian walkways and for light vehicles.

\section{Acknowledgement}

The authors would like to acknowledge financial support for this study by research grant no. 203/PPBGN/6711257 provided by USM/MOE Malaysia.

\section{References}

1. Offenberg, M. 2005. Producing Pervious Pavements Hints for the Engineer, Contractor Placement of Pervious Concrete, Concrete International.

2. Johnston and Kimberly 2009. Pervious Concrete: Past, Present and Future, Concrete Contractor, 9 (2): 22-25

3. Patil, V.R., A.K. Gupta and D.B. Desai, 2010. Use of Pervious Concrete In Construction of Pavement for Improving Their Performance, IOSR Journal of Mechanical and Civil Engineering, 4: 54-56

4. Abustan, I, M.O. Hamzah and M.A. Rashid, 2012. Review of Permeable Pavement Systems in Malaysia Conditions, OIDA International Journal of Sustainable Development, 4(2): 27-36

5. NRMCA, 2004. Concrete in Practice What, Why and How.

6. Li, J., H.N. Xiao and J.Q. Gong, 2008. Laboratory Research on Grading Optimization of Recycled Aggregate Concrete, Journal of Building Materials, 11 (1): 105-110.

7. Dhir, R.K., M.C. Limbachiya and T. Leelwat, 1999. Suitability of Recycled Concrete Aggregate for Use in BS5328 Designated Mixes, Proc. Inst. Civil Eng. Struct. Build, 134 (3): 257-274.

8. Ryu, J.S, 2002. An Experimental Study on the Effect of Recycled Aggregate on Concrete Properties, JMag. Concr. Res, 54 (1): 7-12.

9. Neptune, A.I. and B.J. Putman, 2010. Effect of Aggregate Size and Gradation on Pervious Concrete Mixtures, ACI Materials Journal, 107 (6): 625-631.

10. American Association of State Highway and Transportation, 1993, Guide for Design of Pavement Structures.

11. Lian, C., Y. Zhuge and S. Beecham, 2011, The Relationship Between Porosity and Strength for Porous Concrete, Construction and Building Materials, 25: 4294-4298.

12. Lambert, N., 2014, Compressive, Tensile, Flexural and Bond Strengths of Epoxy Resin, Epoxy resin Strengths Explained, http://www.epoxysystems.com/strength.aspx, web accessed on date April 19, 2014.

13. Yang, J., G. Jiang, 2003, Experimental Study on Properties of Pervious Concrete Pavement Materials, Cement Concrete Research, 33(6): 381-386. 